\title{
Evidence Based Medicine Review of Posterior Thoracolumbar Minimally Invasive Technology
}

\author{
CHARLA R. FISCHER, MD, ${ }^{1}$ BRYAN BEAUBRUN, BS, ${ }^{1}$ JORDAN MANNING, BS, ${ }^{1}$ \\ SHEERAZ QURESHI, MD, ${ }^{2}$ JUAN URIBE, $\mathrm{MD}^{3}$ \\ ${ }^{I}$ NYU Langone Orthopedic Hospital, New York, New York, ${ }^{2}$ Hospital for Special Surgery, New York, New York, ${ }^{3}$ University of South Florida, Tampa, Florida
}

\begin{abstract}
Background: Evaluate the current evidence in meta-analyses on posterior thoracolumbar minimally invasive surgery techniques and outcomes for degenerative conditions.

Methods: A systematic review of the literature from 1950 to 2015.

Results: The review of the literature yielded 34 meta-analysis studies evaluating posterior thoracolumbar minimally invasive techniques and outcomes for degenerative conditions. There were 11 studies included which investigated minimally invasive surgery (MIS) versus open posterior lumbar decompressions. There were 14 studies included which investigated MIS versus open posterior lumbar interbody fusions. Finally, there were 9 studies focused on navigation techniques and radiation safety within MIS procedures.

Conclusions: There are 34 meta-analysis studies evaluating minimally invasive to open thoracolumbar surgery for degenerative disease. The studies show a trend toward decreased estimated blood loss, decreased length of stay, decreased complications, similar fusion rates, improved accuracy, and decreased radiation when minimally invasive techniques are used.

Minimally Invasive Surgery

Keywords: minimally invasive spine surgery, minimally invasive decompression, MIS TLIF, navigation, radiation safety
\end{abstract}

\section{INTRODUCTION}

Minimally invasive surgery (MIS) techniques for spine have gained popularity as surgeons across this specialty have embraced advancements in access systems and imaging technologies. Minimally invasive surgery techniques are currently applied to a variety of spinal pathologies including degenerative disc disease, disc herniation, instability, deformity, fracture, and tumor. Advocates for MIS cite minimal muscle and soft tissue dissection, excellent visualization, and faster recovery time as advantageous when compared to open procedures. ${ }^{1}$ However, despite the initial evidence supporting MIS techniques, traditional open approaches remain the standard of care among spine surgeons, prompting numerous studies dedicated to proving the effectiveness of MIS.

Lumbar microdiscectomy is the most common procedure performed in the United States for patients presenting with low back or leg pain. ${ }^{2}$ Traditionally, these procedures require a significant amount of paraspinal muscle dissection with the exposure maintained by displacing the musculature from the bony elements. ${ }^{3}$ On the contrary, MIS procedures, which use tubular retractor systems, minimize the amount of muscular dissection and thereby have been associated with faster recovery time and decreased intraoperative blood loss. ${ }^{4}$ Similarly, in lumbar fusion surgery, MIS transforaminal lumbar interbody fusion (TLIF) has been shown to have comparable short- and long-term clinical outcomes to its open counterpart with added benefits such as decreased postoperative pain, decreased blood loss, faster recovery times, and shorter length of stay (LOS). ${ }^{5}$

Despite the apparent upsides, MIS surgery is not fully adopted within the spine surgery community. Open surgery advocates cite the increased radiation exposure to patients and providers as their chief criticism of MIS surgery. Certainly, radiation exposure increases with the use of intraoperative fluoroscopy ${ }^{6}$; however, Bindal et al found patient exposure during MIS spine surgery to be low when compared to other common interventional fluoroscopically guided procedures. ${ }^{7}$ Furthermore, technological advancements providing intraoperative 3dimensional computed tomography (3D CT) alter- 
Table 1. Posterior lumbar microdiscectomy or laminectomy.

\begin{tabular}{|c|c|c|c|c|c|}
\hline Authors & $\mathbf{n}$ & Surgical Technique & $\begin{array}{l}\text { MIS Better, } \\
\text { With } P<.05\end{array}$ & MIS = Open & $\begin{array}{l}\text { Open Better, } \\
\text { With } P<.05\end{array}$ \\
\hline $\begin{array}{r}\text { Rasouli et al }^{8} \\
\text { (Cochrane) }^{-}\end{array}$ & 1172 & $\begin{array}{l}\text { MIS versus open } \\
\text { microdiscectomy }\end{array}$ & Shorter LOS, lower SSI & None & None \\
\hline Chang et $\mathrm{al}^{9}$ & 2139 & $\begin{array}{l}\text { MIS versus open } \\
\text { microdiscectomy }\end{array}$ & $\begin{array}{l}\text { Shorter LOS, shorter incision, } \\
\text { less EBL }\end{array}$ & $\begin{array}{l}\text { VAS, hospital costs, surgical } \\
\text { costs, radiation exposure }\end{array}$ & $\begin{array}{l}\text { Risk of recurrent } \\
\text { HNP }\end{array}$ \\
\hline Ji et $\mathrm{al}^{10}$ & 1913 & $\begin{array}{l}\text { MIS versus Open } \\
\text { microdiscectomy }\end{array}$ & $\begin{array}{l}\text { Decreased EBL, smaller } \\
\text { incision shorter LOS, less } \\
\text { complications, outcomes }\end{array}$ & OR time & \\
\hline Shriver et al ${ }^{11}$ & 5390 & $\begin{array}{l}\text { Open versus MIS versus } \\
\text { percutaneous } \\
\text { microdiscectomy }\end{array}$ & $\begin{array}{l}\text { Lower } \mathrm{n} \text { root injury in MIS } \\
\text { versus percutaneous }\end{array}$ & & \\
\hline Wang et $\mathrm{al}^{12}$ & 1012 & $\begin{array}{l}\text { MIS versus open } \\
\text { microdiscectomy }\end{array}$ & Shorter LOS, less EBL & $\begin{array}{l}\text { Short/long-term back pain, } \\
\text { short/long-term leg pain, } \\
\text { ODI, complications }\end{array}$ & \\
\hline Kamper et $\mathrm{al}^{13}$ & 4472 & $\begin{array}{l}\text { Openvs. intralaminar MIS } \\
\text { versus transforaminal } \\
\text { MIS }\end{array}$ & $\begin{array}{l}\text { Intralaminar has less EBL and } \\
\text { shorter LOS }\end{array}$ & & \\
\hline He et $\mathrm{al}^{14}$ & 501 & Microendodiscectomy & $\begin{array}{l}\text { Decreased EBL, decreased } \\
\text { EBL }\end{array}$ & VAS, ODI, complications & OR time \\
\hline Cong et $\mathrm{al}^{15}$ & 1092 & Endoscopic & $\begin{array}{l}\text { Patient satisfaction, lower } \\
\text { EBL, shorter LOS }\end{array}$ & & \\
\hline Phan et al ${ }^{16}$ & 28,487 & $\begin{array}{l}\text { Open versus full } \\
\text { endoscopic versus } \\
\text { microendoscopic }\end{array}$ & $\begin{array}{l}\text { Both endoscopic techniques } \\
\text { had less EBL, shorter OR } \\
\text { time for full endoscopic }\end{array}$ & $\begin{array}{l}\text { ODI, leg pain, overall } \\
\text { complications, recurrence or } \\
\text { reoperation rates, dural } \\
\text { tears, root injury, wound } \\
\text { infections, and } \\
\text { spondylodiscitis }\end{array}$ & \\
\hline Ruan et al ${ }^{17}$ & 1389 & Endoscopic & Shorter OR time, shorter LOS & & $\begin{array}{l}\text { Back pain, ODI, } \\
\text { complications, } \\
\text { reoperations }\end{array}$ \\
\hline Phan et $\mathrm{al}^{18}$ & 841 & $\begin{array}{l}\text { MIS versus open RCT } \\
\text { laminectomies }\end{array}$ & $\begin{array}{l}\text { Higher satisfaction, lower } \\
\text { VAS, shorter LOS, lower } \\
\text { EBL, decreased LOS }\end{array}$ & Durotomy & OR time \\
\hline
\end{tabular}

Abbreviations: EBL, estimated blood loss; HNP, text; LOS, length of stay; MIS, minimally invasive surgery; ODI, Oswestry Disability Index; OR, operating room; RCT, text; SSI, text; VAS, visual analogue scale.

natives to fluoroscopy show promising results not only with regards to radiation safety, but in implant placement accuracy as well. Additional research is necessary to validate these initial studies.

The purpose of this systematic review is to evaluate relative meta-analyses pertaining to the outcomes of posterior lumbar decompression and posterior lumbar fusion surgeries. We will directly compare open and MIS techniques, focusing on operative and patient-reported outcomes. Finally, a complete review of all available literature covering navigation versus fluoroscopy techniques will be conducted, centering on implant accuracy and radiation safety.

\section{METHODS}

A comprehensive search of the literature was performed to identify meta-analysis and high level systematic review studies directly comparing the outcomes of minimally invasive versus open techniques within spine surgery. An electronic search of PubMed (MEDLINE), Ovid MEDLINE, and Cochrane for the past 5 years was conducted using the following search terms: meta-analyses AND lumbar AND minimally invasive or lateral or navigation or radiation safety. The search yielded 8604 original articles, and a reviewer screened all titles and abstracts for inclusion.

During the screening process, any articles meeting the following criteria were excluded from the review: (1) animal studies; (2) literature reviews; (3) biomechanical studies; (4) English available; (5) full text available; (6) nonclinical outcomes studies; (7) nondegenerative conditions such as spinal deformity, trauma, and tumor; (8) nongold standard surgical techniques; (9) nonsurgeon-based treatment (such as endoscopic microdiscectomy by pain management). Kyphoplasty and vertebroplasty were not included due to being part of the treatment for traumatic injuries. The search exclusion strategy yielded 74 articles from the screened literature. Further screening of the titles and abstracts of the studies produced 34 articles included in the review, as shown in Tables 1-3.

The relevant information from each study was extracted and input into tabular form. The follow- 
Table 2. Posterior lumbar fusion.

\begin{tabular}{|c|c|c|c|c|c|}
\hline Authors & $\mathbf{n}$ & Surgical Technique & MIS Better, $P<.05$ & MIS = Open & Open Better, $P<.05$ \\
\hline Khan et $\mathrm{al}^{19}$ & 952 & MIS TLIF versus open & $\begin{array}{l}\text { EBL, LOS, late VAS back } \\
\text { pain }\end{array}$ & $\begin{array}{l}\text { Fusion rate, OR time, early } \\
\text { VAS back, early ODI, and } \\
\text { late ODI }\end{array}$ & Radiation exposure \\
\hline Jin-tao et $\mathrm{al}^{20}$ & & $\begin{array}{l}\text { MIS TLIF/PLIF versus } \\
\text { open }\end{array}$ & & Complication, fusions & Readmission/reoperation \\
\hline Bevevino et $\mathrm{al}^{21}$ & 408 & MIS versus open TLIF & & Fusion rate & \\
\hline Lin et $\mathrm{al}^{22}$ & 994 & MIS versus open TLIF & $\begin{array}{l}\text { LOS, EBL, postoperative } \\
\text { VAS }\end{array}$ & $\begin{array}{l}\text { ODI, complications, fusions, } \\
\text { OR time }\end{array}$ & Radiation exposure \\
\hline $\mathrm{Wu}$ et $\mathrm{al}^{23}$ & 1028 & MIS versus open TLIF & & Fusion rate, complications & \\
\hline Goldstein et $\mathrm{al}^{24}$ & 1662 & MIS versus open TLIF & $\begin{array}{l}\text { EBL, LOS, time to } \\
\text { ambulation, medical } \\
\text { complications, } \\
\text { postoperative ODI }\end{array}$ & $\begin{array}{l}\text { OR time, surgical } \\
\text { complications, fusion, } \\
\text { reoperations }\end{array}$ & \\
\hline Li et $\mathrm{al}^{25}$ & 770 & MIS versus open TLIF & $\begin{array}{l}\text { Adjacent segment } \\
\text { degeneration and disease }\end{array}$ & & \\
\hline Kim et $\mathrm{al}^{6}$ & 619 & MIS versus open TLIF & & & Radiation 2.4 times less \\
\hline Sun et $\mathrm{al}^{26}$ & 830 & MIS versus open TLIF & $\begin{array}{l}\text { EBL, postoperative } \\
\text { drainage, LOS }\end{array}$ & ODI, VAS, complications & \\
\hline Xie et $\mathrm{al}^{27}$ & 1967 & MIS versus open TLIF & $\begin{array}{l}\text { ODI, VAS, early } \\
\text { ambulation, LOS, EBL }\end{array}$ & $\begin{array}{l}\text { Fusion, reoperations, } \\
\text { complications, OR time }\end{array}$ & \\
\hline Phan et $\mathrm{al}^{28}$ & 384 & $\begin{array}{l}\text { Direct hospital costs, EBL, } \\
\text { LOS, complications }\end{array}$ & Cost effectiveness & OR time & \\
\hline Goldstein et $\mathrm{al}^{29}$ & 9397 & $\begin{array}{l}\text { Direct and indirect costs, } \\
\text { OR time, EBL, LOS }\end{array}$ & Cost effectiveness & Complications & \\
\hline Vertuani et $\mathrm{al}^{30}$ & NA & Direct hospital costs & Cost effectiveness & & \\
\hline $\begin{array}{l}\text { Keorochana } \\
\quad \text { et } \mathrm{al}^{31}\end{array}$ & 9506 & $\begin{array}{l}\text { MIS TLIF versus MIS } \\
\text { LLIF }\end{array}$ & & $\begin{array}{l}\text { Equal pain relief, fusion, can } \\
\text { complications }\end{array}$ & \\
\hline
\end{tabular}

Abbreviations: EBL, estimated blood loss; LLIF, lateral lumbar interbody fusion; LOS, length of stay; MIS, minimally invasive surgery; NA, not available; ODI,

Oswestry Disability Index; OR, operating room; PLIF, posterior lumbar interbody fusion; TLIF, transforaminal lumbar interbody fusion; VAS, visual analogue scale.

ing information was collected: patient population including sample size, outcome measures, and surgical technique used. When included in the article, the statistical significance of the findings was collected and included in the table.

\section{RESULTS}

The search guidelines outlined above yielded 34 studies that met the inclusion criteria, as shown in Figure 1. All of these studies compared open

Table 3. Navigation techniques.

\begin{tabular}{|c|c|c|c|c|c|}
\hline Authors & $\mathbf{n}$ & Technique & $\begin{array}{l}\text { Navigation Better, } \\
\qquad P<.05\end{array}$ & $\begin{array}{l}\text { Navigation }= \\
\text { Free Hand }\end{array}$ & $\begin{array}{l}\text { Free Hand Better, } \\
\qquad P<.05\end{array}$ \\
\hline Bourgeois et $\mathrm{al}^{32}$ & 599 & $\begin{array}{l}\text { 3D CT Nav versus 2D } \\
\text { Fluoro Nav }\end{array}$ & 3D decreased breach rates & & \\
\hline Tjardes et $\mathrm{al}^{33}$ & $\begin{array}{l}373 \text { cervical, } \\
450 \text { thoracic, } \\
413 \text { lumbar }\end{array}$ & 3D CT Nav versus FH & $\begin{array}{l}\text { Lumbar/thoracolumbar screw } \\
\text { placement, decrease radiation } \\
\text { time and dose }\end{array}$ & & $\begin{array}{c}\text { Thoracic screw } \\
\text { placement }\end{array}$ \\
\hline Gelalis et $\mathrm{al}^{34}$ & 1105 patients & $\begin{array}{l}\text { FH, 3D CT Nav, 2D } \\
\text { Fluoro Nav }\end{array}$ & $\begin{array}{l}\text { Screw placement, breach } \\
\text { laterally/free hand breach } \\
\text { medially }\end{array}$ & & \\
\hline $\begin{array}{l}\text { Kosmopoulos } \\
\text { et } \mathrm{al}^{35}\end{array}$ & 37, 337 screws & 3D CT Nav versus FH & $\begin{array}{l}\text { Screw placement lumbar and } \\
\text { cervical }\end{array}$ & $\begin{array}{c}\text { Thoracic screw } \\
\text { placement }\end{array}$ & \\
\hline Moses et $\mathrm{al}^{36}$ & $\mathrm{~N} / \mathrm{A}$ & $\begin{array}{l}\text { 3D CT Nav versus FH } \\
\text { MIS }\end{array}$ & $\begin{array}{l}\text { Screw placement, decrease } \\
\text { neuromonitoring changes, } \\
\text { decrease radiation exposure }\end{array}$ & & \\
\hline Mason et $\mathrm{al}^{37}$ & 1973 patients & $\begin{array}{l}\text { 3D Fluoro Nav versus } \\
\text { 2D Fluoro Nav }\end{array}$ & $\begin{array}{l}\text { Screw placement, decreased } \\
\text { neurologic injury, decrease } \\
\text { breach rate }\end{array}$ & & \\
\hline Liu et $\mathrm{al}^{38}$ & 257 patients & $\begin{array}{l}\text { Robot assisted versus } \\
\text { FH }\end{array}$ & & $\begin{array}{l}\text { Screw placement } \\
\text { accuracy }\end{array}$ & \\
\hline Srinivasan et $\mathrm{al}^{39}$ & NA & $\begin{array}{l}\text { Radiation safety all } \\
\text { spine }\end{array}$ & $\begin{array}{l}\text { MIS pedicle screw placement } \\
\text { and MIS TLIF have highest } \\
\text { dose }\end{array}$ & & \\
\hline Yu et $\mathrm{al}^{40}$ & 303 & $\begin{array}{l}\text { Radiation safety FH } \\
\text { Fluoro versus 3D CT } \\
\text { Nav MIS }\end{array}$ & $\begin{array}{l}\text { Lower surgical team radiation } \\
\text { dose }\end{array}$ & & Lower patient dose \\
\hline
\end{tabular}




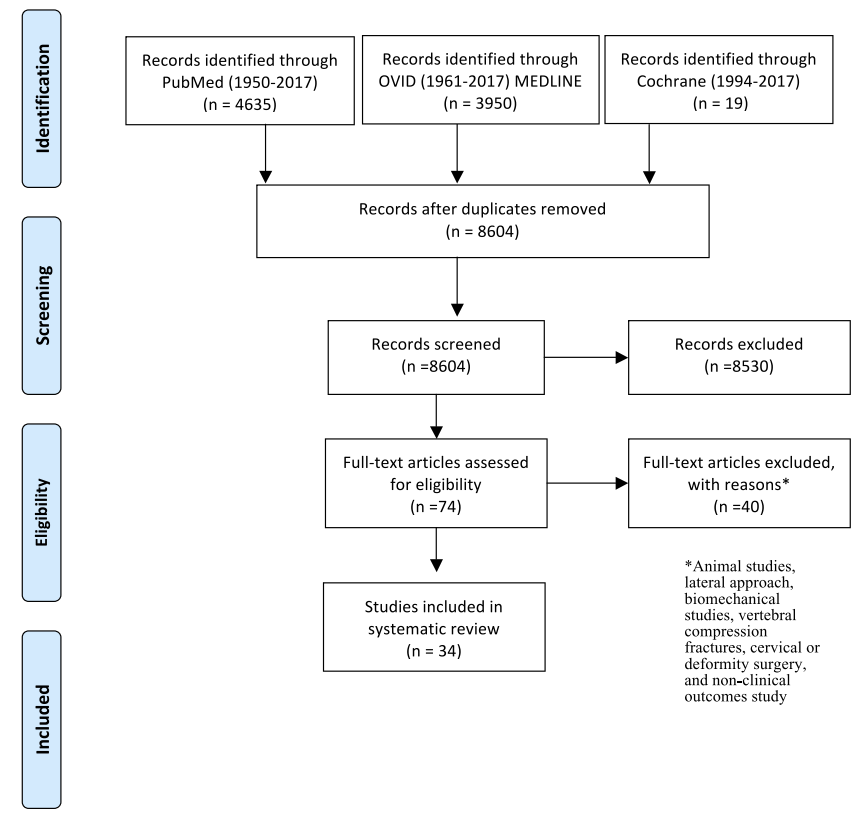

Figure 1. PRISMA flowchart for systematic review of meta-analysis studies on minimally invasive surgery techniques.

procedures to MIS procedures in some capacity, focusing primarily on operative efficiency and patient outcomes. There were 11 studies included which investigated MIS versus open posterior lumbar decompressions, shown in Table 1. There were 14 studies included which investigated MIS versus open posterior lumbar interbody fusions (PLIFs), shown in Table 2. Finally, there were 9 studies focused on navigation techniques and radiation safety within MIS procedures, shown in Table 3.

\section{Posterior Lumbar Decompression}

There were several studies in the literature evaluating the difference between open and minimally invasive lumbar decompression surgery, summarized in Table 1. Six studies pertained to MIS versus open microdiscectomy procedures. Four studies compared endoscopic versus open microdiscectomies. Finally, 1 study looked at MIS and open laminectomies. These studies reported procedural outcomes in terms of operative parameters and patient reported outcomes.

Of the 6 studies comparing MIS and open microdiscectomy procedures, 4 showed significantly shorter LOS associated with MIS procedures. ${ }^{8-10,12}$ Three studies found significantly less estimated blood loss (EBL) associated with MIS, ${ }^{9,10,12}$ including 2 that reported shorter incision length..$^{9,10}$ Rasouli et $\mathrm{al}^{8}$ performed a Cochrane review in
2014 and found low quality evidence in favor of MIS for improved leg pain and in favor of open surgery for back pain, but these differences were likely not clinically significant. ${ }^{8}$ In 1 study, using both a systematic review and meta-analysis approach, Kamper et $\mathrm{al}^{13}$ separately compared conventional microdiscectomies with MIS interlaminar discectomies and MIS transforaminal discectomies. Their findings suggest that interlaminar discectomies decrease EBL and LOS, while MIS transforaminal discectomies were inconclusive due to a low number of studies. Additional MIS benefits were less nerve root damage, ${ }^{11}$ fewer complications, ${ }^{10}$ and lower rates of surgical site infection. ${ }^{8}$ Minimally invasive surgery discectomy techniques were found to be equivalent to open procedures in several categories. Wang et $\mathrm{al}^{12}$ examined 1012 decompressions, finding no statistical difference when comparing short- and long-term back pain, short- and long-term neck pain, Oswestry Disability Index (ODI) scores, and complications between surgical approaches. In a study including 2139 decompressions, Chang et $\mathrm{al}^{9}$ exhibited comparable data for visual analogue scale (VAS) scores, hospital costs, surgical costs, as well as radiation exposure; however, this study also found an increased risk of recurrent herniated nucleus pulposus associated with MIS, providing the only support for open microdiscectomy surgery.

Four meta-analysis studies examined open, endoscopic, and microendoscopic discectomy approaches. Consistent with MIS approaches, both endoscopic and microendoscopic approaches yielded statistically better results than open procedures with regard to $\mathrm{EBL}^{14-16}$ and $\operatorname{LOS}^{15,17}$; however, other patient outcome measures were inconclusive. Cong et $\mathrm{al}^{15}$ performed a meta-analysis review of endoscopic and open microdiscectomies in 1092 patients. In addition to less EBL and shorter LOS, they concluded that endoscopic procedures had statistically better patient outcome scores (endoscopic: $93.21 \%$, open: $80 \%, P<.05$ ). On the other hand, Ruan et $\mathrm{al}^{17}$ performed a meta-analysis including 7 studies with 1389 patients. While the endoscopic group had a shorter operating room (OR) time and LOS, VAS back pain, ODI, complication rate, and reoperation rate were statistically better in the open group. ${ }^{16}$ Finally, beyond EBL and LOS, 2 studies found no statistical difference when comparing outcomes (VAS scores, ODI scores and complication rates, reoperation 
rates) between the 2 groups. In summary, although endoscopic and microendoscopic discectomy procedures improve operative time and EBL, additional research is necessary to resolve the advantages and disadvantages pertaining to patient outcomes and complications.

One study in our review was unique in nature. Phan et $\mathrm{al}^{41}$ performed a meta-analysis study evaluating open versus MIS laminectomies in 841 patients. Overall, MIS laminectomies had higher satisfaction rates $(84 \%$ versus $75 \%)$ coinciding with lower VAS pain scores $(P<.001)$. Additionally, MIS laminectomies displayed marked decrease in EBL $(P<.001)$ and hospital stay $(2.1$ days; $P<$ $.001) .^{41}$ Longer operative time of 11 minutes was associated with the MIS procedures $(P=.001)$, however, this appears to have little clinical significance.

\section{Posterior Interbody Fusion}

There were 14 meta-analysis studies comparing open versus MIS PLIFs and TLIFs, summarized in Table 2. Overall, MIS fusions positively affected the following outcome parameters: EBL, LOS, and cost effectiveness. While in 2 studies VAS and ODI scores were improved in the MIS fusion patients, these metrics were more commonly equal among the 2 approaches. Fusion and complications rates were also comparable between MIS and open techniques; however, 1 study of adjacent segment disease showed promising results for MIS TLIFs. Those studies including radiation exposure found significantly higher levels of exposure with the MIS technique.

Two studies summarize the overall findings comparing MIS and open fusion procedures. First, Khan et al performed a meta-analysis on 30 studies of TLIF surgeries using both MIS and open techniques. While no significant differences existed in ODI at 6 months and 1 year and VAS scores at 6 months, operative time, and fusion rates, there were significant advantages associated with MIS TLIFs. One-year postoperative VAS scores, lower EBL, and a lower rate of complications improved within MIS TLIF patients $(P<.001)$. Radiation exposure was the only drawback of MIS TLIF procedures displaying approximately 38 extra seconds of fluoroscopy time. ${ }^{19}$ Next, Sun et al conducted a meta-analysis comparing MIS to open TLIF in 12 studies with 830 patients. Consistent with the Khan et al study, Sun et al found minimally invasive patients had less EBL, shorter hospital stay, and less postoperative drainage. There was no difference in ODI, VAS, or complications. ${ }^{26}$

Among the present meta-analysis literature, both open and MIS techniques have high fusion rates. Bevevino et al performed a meta-analysis including 7 studies and 408 patients, assessing fusions using postoperative CT scans. For MIS and open TLIFs in which polyetheretherketone or allograft cages were used in conjunction with local autograft bone, equal fusion rates were reported $(94.7 \%$ overall fusion). ${ }^{20}$ Several other studies show equal fusion rates among MIS and open TLIF procedures, while supporting MIS procedures when considering LOS, EBL, ODI, and VAS scores. ${ }^{22,23,27}$ In addition to equal fusion rates, these studies displayed comparable complication rates as well.

With regard to complications, Goldstein et $\mathrm{al}^{29}$ reviewed 26 studies (856 MIS patients and 806 open patients), concluding equal results in patient outcomes and surgical complication rates, but reported a decrease in medical complication rates in the MIS group versus the open group. Furthermore, MIS TLIFs are believed to reduce adjacent segment disorders when compared to open surgery. Li et $\mathrm{al}^{25}$ completed a meta-analysis examining adjacent segment pathology in 9 studies with 770 patients. They found significantly lower rates of adjacent segment pathology in patients who underwent MIS fusion surgery. ${ }^{25}$ Furthermore, Jin-tao et al published a comparison of MIS versus open PLIF/ TLIFs, noting the complication rates for both were similar. However, MIS procedures tended to have a higher revision/readmission rate, which they attributed to the deep learning curve associated with the procedure. $^{20}$

Three studies featured cost analysis of open and MIS fusion procedures. Phan et $\mathrm{al}^{42}$ studied cost effectiveness, reporting hospital costs were lower in MIS surgery, which may be attributable to the decrease in complications, EBL, and LOS. In a 45study meta-analysis comparing 3472 MIS procedures and 5925 open procedures, Goldstein et $\mathrm{al}^{24}$ determined that overall MIS procedures had decreased OR time, EBL, LOS, and equal patientreported outcomes and complication rates. Additionally, MIS procedures resulted in approximately $2.5-49.3 \%$ cost savings. Finally, Vertuani et $\mathrm{al}^{30}$ published a meta-analysis with an accompanying cost model, which revealed MIS total cost savings per procedure of $€ 973$ in Italy and $€ 1666$ in the 
United Kingdom and an improvement of 0.004 quality-adjusted life-year over 2 years.

There was 1 meta-analysis study performed by Keorochana et $\mathrm{al}^{31}$ that compared outcomes for lateral lumbar interbody fusion (LLIF) to MIS TLIF. The study included 9506 patients, of which 3778 underwent LLIFs, while 5728 patients underwent MIS TLIFs. Overall, MIS TLIF techniques exhibited better leg pain improvement, postoperative back pain, ODI scores, equivalent fusion rates, and decreased complication rates. ${ }^{31}$ This is similar to results on lateral approach surgeries found by other studies, but these studies are not systematic reviews. ${ }^{43,44}$

Within our systematic review, radiation exposure was the most common issue related to MIS lumbar fusions. Three studies reported greater radiation exposure when directly comparing MIS and open lumbar fusions. ${ }^{6,19,22}$ In a meta-analysis of 8 cohort studies with a total of 619 patients, Kim et $\mathrm{al}^{6}$ recorded fluoroscopy time and radiation exposure. Mean fluoroscopy time was 39.42 to 94.21 seconds, while radiation exposure was 0.66 to $1.58 \mathrm{mSv}$ for open and MIS procedures, respectively. These findings represent a 2.4-fold increase in radiation when comparing MIS to open TLIF procedures and suggest that clinicians should strive to use the lowest amount of radiation possible. ${ }^{6}$

\section{Navigation Techniques and Radiation Safety}

Nine studies reviewed the use of navigation techniques as well as radiation safety, summarized in Table 3. Seven of the studies focused on the accuracy of pedicle screw placement between the following techniques: 3D CT-based navigation systems (3D CT Nav), 2-dimensional fluoroscopybased navigation (2D Fluoro Nav), free hand with fluoroscopy (FH Fluoro), and free hand (FH). Metrics included pedicle screw accuracy (screw fully enclosed in bone), rates of pedicle breaches, neurologic incidents, as well as dose rate and radiation time. Two studies specifically addressed radiation safety and described the necessary steps to minimize exposure.

Seven meta-analysis studies evaluated the outcomes of various pedicle screw insertion techniques. Pedicle screw placement was consistently more accurate when 3D CT Nav techniques were used in cervical and lumbar screw placement, but inconclusive for thoracic screw placement. Gelalis et al compared screw placement accuracy for $\mathrm{FH}$,
FH Fluoro, 2D Fluoro Nav, and 3D CT Nav. Screw insertion accuracies were as follows: FH 69-94\%, FH Fluoro $28-85 \%$, 2D Fluoro Nav $81-92 \%$, and 3D CT Nav 89-100\%. Interestingly, inaccurate FH screws tended to breach medially, while inaccurate 3D CT Nav screws breached laterally. ${ }^{34}$ In a similar literature review, Tjardes et al reviewed 23 cervical, 24 thoracic, and 24 lumbar spine studies concerning image guided screw placement. Three-dimensional CT Nav significantly improved screw placement in the cervical and lumbar regions; however, thoracic pedicle screw placement was more accurate using FH technique. ${ }^{33}$ Kosmopoulos et al confirmed 3D CT Nav improves accuracy in the cervical and lumbar regions, yet found no added advantage in the thoracic levels. ${ }^{35}$ Finally, Mason et al abstracted and analyzed datasets from 30 studies including 12 FH Fluoro, 8 2D Fluoro Nav, and 20 3D CT Nav. Using 3D CT Nav consistently resulted in higher screw placement accuracy $(95.5 \%)$ when compared to FH Fluoro and 2D Fluoro Nav (68.1 and 84.3\%, respectively). In conjunction with accurate screw placement, breach rates and neurologic injuries decreased with 3D CT Nav. ${ }^{32,37}$

Moses et al applied the same review process for advanced image guidance in 52 studies pertaining to MIS screw placement. As in open procedures, 3D CT Nav outperformed FH Fluoro techniques by a wide margin (98.8 to $79.0 \%$ ). Additionally, 3D CT $\mathrm{Nav}$ decreased neuromonitoring changes, radiation exposure, and screw placement time (54 to 89 minutes) ${ }^{40}$ In an effort to further optimize pedicle screw accuracy while reducing radiation exposure, physicians have begun to incorporate robot-assisted technology. To evaluate the efficacy, Liu et $\mathrm{al}^{38}$ published a meta-analysis on pedicle screw accuracy between robot-assisted and FH techniques. Three of the 5 studies showed greater accuracy using the robot-assisted approach; however, they were not statistically different results. Also, the other 2 studies provided evidence for more accurate $\mathrm{FH}$ approaches. Therefore, the meta-analysis was unable to determine which technique was more accurate.

Two meta-analyses looked specifically at the radiation exposure of navigation techniques. First, Srinivasan et al presented a literature review based on 11 studies examining the increased radiation exposure due to fluoroscopy. Minimally invasive surgery pedicle screw placement and TLIF procedures had the highest radiation doses. Given the 
efficiency of these innovations and therefore likelihood of widespread implementation, Srinivasan et al suggested that surgeons begin to take the following precautions in minimizing radiation exposure: time, distance, and shielding. Furthermore, they recommended minimizing the use of single-shot fluoroscopy, increasing the use of pulsed fluoroscopy and the appropriate manipulation of the fluoroscopic equipment. ${ }^{39}$ On the same note, Yu et $\mathrm{al}^{40}$ reviewed 22 studies pertaining to increased radiation exposure associated with MIS techniques. Free hand Fluoro resulted in higher radiation effecting the surgical team; however, 3D CT Nav increased radiation affecting the patient, although it was lower than the amount in a normal CT scan. As a result, they suggested intraoperative 3D CT Nav should be a low dose protocol in order to reduce the amount of radiation exposure to the patient. ${ }^{40}$

\section{DISCUSSION}

After conducting a thorough literature review, the results of 11 meta-analyses evaluating the outcomes of traditional open to minimally invasive microdiscectomy or laminectomy, 14 studies evaluating traditional open lumbar fusion to minimally invasive lumbar fusion, and 9 studies evaluating navigation and radiation safety were included in this study. There is evidence that MIS techniques lead to a shorter LOS, decreased complication rates, and improved accuracy for all of these minimally invasive procedures. Furthermore, important outcome metrics such as fusion rates, VAS scores, and ODI scores are equivalent. Increased radiation exposure is higher during these procedures; however, implementing 3D CT Nav can significantly reduce exposure.

Substantial literature exists associating MIS and endoscopic discectomies with shorter LOS and lesser EBL when compared to open procedures. $^{8-10,12-14,16,17}$ While the literature is less conclusive with regard to patient outcomes between endoscopic and open procedures, several studies highlight MIS discectomies as being superior within this arena. $8,10,12$ Some early studies showed that MIS may be inferior in terms of relief of leg pain, low back pain, and rehospitalization. As techniques improved, these differences in clinical outcome became equivalent. With the evidence showing some improved hospital metrics such as LOS and EBL, and equivalent clinical outcome metrics, MIS microdiscectomies may have benefits over open microdiscectomies.

In addition to microdiscectomies, current literature supports MIS lumbar fusions over their open counterparts in a number of variables. The largest procedural benefits associated with MIS fusions are decreased EBL and LOS. ${ }^{16,19,22,26,27,29}$ Considering these benefits are consistently associated with equivalent or better patient-reported outcomes, fusion rates, and complications, physicians can confidently implement MIS lumbar fusions into their practice without fear of reprisal. ${ }^{19,20,22,23,25-27,29}$ Finally, multiple studies provide evidence that the shorter LOS results in cost savings which more than compensate for the additional instrumentation costs. ${ }^{30,45,46}$ With the rising costs of health care, a safe, reliable, and cost-effective solution such as the MIS TLIF could be extremely beneficial.

Those supporting open surgery claim the learning curve and additional radiation exposure outweigh the benefits to MIS surgery. ${ }^{47,48}$ Therefore, navigation and radiation safety is considered an important part of evaluating the current state of minimally invasive lumbar surgery. As MIS developed, the techniques initially employed a higher use of fluoroscopy compared to traditional open procedures. ${ }^{33,36,40}$ With the high risk of radiation exposure to the surgeon, the surgical team, and the patient, ways to decrease this are of high value in spine surgery. As navigation techniques become more sophisticated, the radiation exposure is much less, while allowing for improved pedicle screw placement accuracy. ${ }^{33,36,40}$ Given these findings, navigation appears to be the solution to high radiation exposure associated with MIS lumbar fusion.

\section{CONCLUSIONS}

Trends in MIS posterior decompressions versus open posterior decompressions show that there is decreased EBL, decreased LOS, decreased complication rates, and equivalent overall postoperative patient outcomes. Concerning MIS posterior interbody fusions, MIS procedures have decreased EBL, decreased LOS, decreased complication rates, overall better postoperative patient outcomes and better cost effectiveness. When examining the different types of screw placement techniques, there is an overall reported increase in accuracy with 3D CT Nav versus all other options. Regarding radiation 
safety, the general consensus within the reviewed literature was that there was a decrease in patient radiation when using $\mathrm{CT}$ navigation, but the higher radiation amount for the surgical team should be decreased by implementing the low dose CT protocol.

\section{REFERENCES}

1. Barbagallo GM, Yoder E, Dettori JR, Albanese V. Percutaneous minimally invasive versus open spine surgery in the treatment of fractures of the thoracolumbar junction: a comparative effectiveness review. Evid Based Spine Care J. 2012;3(3):43-49.

2. Weinstein JN, Tosteson TD, Lurie JD, et al. Surgical vs nonoperative treatment for lumbar disk herniation. Jama. 2006;296(20):2441.

3. Osterman H, Seitsalo S, Karppinen J, Malmivaara A. Effectiveness of microdiscectomy for lumbar disc herniation: a randomized controlled trial with 2 years of follow-up. Spine (Phila Pa 1976). 2006;31(21):2409-2414.

4. Li CH, Yew AY, Kimball JA, McBride DQ, Wang JC, Lu DC. Comparison of operating field sterility in open versus minimally invasive microdiscectomies of the lumbar spine. Surg Neurol Int. 2013;4(Suppl 5):S295-S298.

5. Skovrlj B, Gilligan J, Cutler HS, Qureshi SA. Minimally invasive procedures on the lumbar spine. World $J$ Clin Cases WJCC. 2015;3(1):1-9.

6. Kim $\mathrm{CH}$. How high are radiation-related risks in minimally invasive transforaminal lumbar interbody fusion compared with traditional open surgery? A meta-analysis and dose estimates of ionizing radiation. Clin Spine Surg. 2016;29(2):52-59.

7. Bindal RK, Glaze S, Ognoskie M, Tunner V, Malone R, Ghosh S. Surgeon and patient radiation exposure in minimally invasive transforaminal lumbar interbody fusion. $J$ Neurosurg Spine. 2008;9(6):570-573.

8. Rasouli M, Rahimi-Movaghar V, Shokraneh F, MoradiLakeh M, Chou R. Minimally invasive discectomy versus microdiscectomy/open discectomy for symptomatic lumbar disc herniation (Review). Cochrane Database Syst Rev. 2014;4(9):912.

9. Chang X, Chen B, Li H, Han X, Zhou Y, Li C. The safety and efficacy of minimally invasive discectomy: a meta-analysis of prospective randomised controlled trials. Int Orthop. 2014;38(6): 1225-1234.

10. Ji S, Shao Q, Wang Y, Liu J. Efficacy comparison between minimally invasive and conventional surgery for lumbar disc herniation in Chinese Han population: a metaanalysis. Spinal Cord. 2014;52(10):734-739.

11. Shriver MF, Xie JJ, Tye EY, et al. Lumbar microdiscectomy complication rates: a systematic review and metaanalysis. Neurosurg Focus. 2015;39(4):E6.

12. Wang XS, Sun RF, Ji Q, et al. A meta-analysis of interlaminar minimally invasive discectomy compared to conventional microdiscectomy for lumbar disk herniation. Clin Neurol Neurosurg. 2014;127:149-157.

13. Kamper SJ, Ostelo RWJG, Rubinstein SM, et al. Minimally invasive surgery for lumbar disc herniation: a systematic review and meta-analysis. Eur Spine J. 2014;23(5):1021-1043.
14. He JL, Xiao SW, Wu ZJ, Yuan ZC. Microendoscopic discectomy versus open discectomy for lumbar disc herniation: a meta-analysis. Eur Spine J. 2016;25(5):1373-1381.

15. Cong L, Zhu Y, Tu G. A meta-analysis of endoscopic discectomy versus open discectomy for symptomatic lumbar disk herniation. Eur Spine J. 2016;25(1):134-143.

16. Phan K, Xu J, Schultz K, et al. Full-endoscopic versus micro-endoscopic and open discectomy: a systematic review and meta-analysis of outcomes and complications. Clin Neurol Neurosurg. 2017;154:1-12.

17. Ruan W, Feng F, Liu Z, Xie J, Cai L, Ping A. Comparison of percutaneous endoscopic lumbar discectomy versus open lumbar microdiscectomy for lumbar disc herniation: a meta-analysis. Int J Surg. 2016;31:86-92.

18. Phan K, Xu J, Schultz K, et al. Full-endoscopic versus micro-endoscopic and open discectomy. A systematic review and meta-analysis of outcomes and complications. Clin Neurol Neurosurg 2017;154:1-12.

19. Khan NR, Clark AJ, Lee SL, Venable GT, Rossi NB, Foley KT. Surgical outcomes for minimally invasive vs open transforaminal lumbar interbody fusion: an updated systematic review and meta-analysis. Neurosurgery. 2015;77(6):847-874.

20. Jin-tao Q, Yu T, Mei W, et al. Comparison of MIS vs. open PLIF/TLIF with regard to clinical improvement, fusion rate, and incidence of major complication: a meta-analysis. Eur Spine J. 2015;24(5):1058-1065.

21. Bevevino AJ, Kang DG, Lehman RA, Van Blarcum GS, Wagner SC, Gwinn DE. Systematic review and meta-analysis of minimally invasive transforaminal lumbar interbody fusion rates performed without posterolateral fusion. J Clin Neurosci. 2014;21(10):1686-1690.

22. Lin Y, Chen W, Chen A, Li F. Comparison between minimally invasive and open transforaminal lumbar interbody fusion: a meta-analysis of clinical results and safety outcomes. $J$ Neurol Surg A Cent Eur Neurosurg. 2016;77(1):2-10.

23. Wu RH, Fraser JF, Härtl R. Minimal access versus open transforaminal lumbar interbody fusion. Spine (Phila Pa 1976). 2010;35(26):2273-2281.

24. Goldstein CL, Phillips FM, Rampersaud YR. Comparative effectiveness and economic evaluations of open versus minimally invasive posterior or transforaminal lumbar interbody fusion. Spine (Phila Pa 1976). 2016;41(8):1.

25. Li XC, Huang CM, Zhong CF, Liang RW, Luo SJ. Minimally invasive procedure reduces adjacent segment degeneration and disease: new benefit-based global meta-analysis. PLoS One. 2017;12(2):1-14.

26. Sun Z, Li W, Zhao Y, Qiu G. Comparing minimally invasive and open transforaminal lumbar interbody fusion for treatment of degenerative lumbar disease: a meta-analysis. Chin Med J (Engl). 2013;126(20):3962-3971.

27. Xie L, Wu W-J, Liang Y. Comparison between minimally invasive transforaminal lumbar interbody fusion and conventional open transforaminal lumbar interbody fusion: an updated meta-analysis. Chin Med J (Engl). 2016;129(16):1969-1986.

28. Phan K, Rao PJ, Kam AC, Mobbs RJ. Minimally invasive versus open transforaminal lumbar interbody fusion for treatment of degenerative lumbar disease: systematic review and meta-analysis. Eur Spine J 2015;24(5):1017-1030.

29. Goldstein C, Macwan K, Sundararajan K, Rampersaud YR. Perioperative outcomes and adverse events of minimally 
invasive versus open posterior lumbar fusion: meta-analysis and systematic review. J Neurosurg Spine. 2016;24(March):416-427.

30. Vertuani S, Nilsson J, Borgman B, et al. A costeffectiveness analysis of minimally invasive versus open surgery techniques for lumbar spinal fusion in Italy and the United Kingdom. Value Heal. 2015;18(6):810-816.

31. Keorochana G, Setrkraising K, Woratanarat P, Arirachakaran A, Kongtharvonskul J. Clinical outcomes after minimally invasive transforaminal lumbar interbody fusion and lateral lumbar interbody fusion for treatment of degenerative lumbar disease: a systematic review and meta-analysis. Neurosurg Rev. 2018;41(3):755-770.

32. Bourgeois AC, Faulkner AR, Bradley YC, et al. Improved accuracy of minimally invasive transpedicular screw placement in the lumbar spine with 3-dimensional stereotactic image guidance. J Spinal Disord Tech. 2015;28(9):324-329.

33. Tjardes $\mathrm{T}$, Shafizadeh $\mathrm{S}$, Rixen D, et al. Image-guided spine surgery: state of the art and future directions. Eur Spine J. 2010;19(1):25-45.

34. Gelalis ID, Paschos NK, Pakos EE, et al. Accuracy of pedicle screw placement: a systematic review of prospective in vivo studies comparing free hand, fluoroscopy guidance and navigation techniques. Eur Spine J. 2012;21(2):247-255.

35. Kosmopoulos V, Schizas C. Pedicle screw placement accuracy: a meta-analysis. Spine (Phila Pa 1976). 2007;32(3): E111-E120.

36. Moses ZB, Mayer RR, Strickland BA, et al. Neuronavigation in minimally invasive spine surgery. Neurosurg Focus. 2013;35(2):E12.

37. Mason A, Paulsen R, Babuska JM, et al. The accuracy of pedicle screw placement using intraoperative image guidance systems. J Neurosurg Spine. 2014;20(2):196-203.

38. Liu H, Chen W, Wang Z, Lin J, Meng B, Yang H. Comparison of the accuracy between robot-assisted and conventional freehand pedicle screw placement: a systematic review and meta-analysis. Int J Comput Assist Radiol Surg 2016;11(12):2273-2281.

39. Srinivasan D, Than KD, Wang AC, et al. Radiation safety and spine surgery: systematic review of exposure limits and methods to minimize radiation exposure. World Neurosurg. 2014;82(6):1337-1343.

40. Yu E, Khan SN. Does less invasive spine surgery result in increased radiation exposure? A systematic review. Clin Orthop Relat Res. 2014;472(6):1738-1748.

41. Phan K, Mobbs RJ. Minimally invasive versus open laminectomy for lumbar stenosis - a systematic review and meta-analysis. Spine (Phila Pa 1976). 2015;41(2):91-100.
42. Phan K, Hogan JA, Mobbs RJ. Cost-utility of minimally invasive versus open transforaminal lumbar interbody fusion: systematic review and economic evaluation. Eur Spine $J$. 2015;24(11):2503-2513.

43. Uribe JS, Deukmedjian AR. Visceral, vascular, and wound complications following over 13,000 lateral interbody fusions: a survey study and literature review. Eur Spine J. 2015;24(Suppl 3):386-396.

44. Lehmen JA, Gerber EJ. MIS lateral spine surgery: a systematic literature review of complications, outcomes, and economics. Eur Spine J. 2015;24(S3):287-313.

45. Uddin OM, Haque R, Sugrue PA, et al. Cost minimization in treatment of adult degenerative scoliosis. $J$ Neurosurg Spine. 2015;23(6):798-806.

46. Lucio JC, VanConia RB, DeLuzio KJ, Lehmen JA, Rodgers JA, Rodgers WB. Economics of less invasive spinal surgery: an analysis of hospital cost differences between open and minimally invasive instrumented spinal fusion procedures during the perioperative period. Risk Manag Healthc Policy. 2012;5:65-74.

47. Funao H, Ishii K, Momoshima S, et al. Surgeons' exposure to radiation in single- and multi-level minimally invasive transforaminal lumbar interbody fusion; a prospective study. Fehlings M, ed. PLoS One. 2014;9(4):e95233.

48. Sclafani JA, Kim CW. Complications associated with the initial learning curve of minimally invasive spine surgery: a systematic review. Clin Orthop Relat Res. 2014;472(6):17111717.

Disclosures and COI: The authors received no funding for this study and report no conflicts of interest.

Corresponding Author: Charla Fischer, MD, NYU Langone Orthopedic Hospital, Address, New York, NY 10003. Phone: (646) 356-9415; Fax: (646) 356-9413; Email: charla.fischer@nyumc.org.

Published 21 December 2018

This manuscript is generously published free of charge by ISASS, the International Society for the Advancement of Spine Surgery. Copyright @ 2018 ISASS. To see more or order reprints or permissions, see http://ijssurgery.com. 